\title{
Global diastolic function in endurance athletes: three-dimensional volume tracking of the mitral annulus with cine-CMR
}

\author{
Vincent Wu ${ }^{1 *}$, Sohae Chung ${ }^{1}$, Myra S Cocker ${ }^{4}$, Jacqueline Flewitt ${ }^{2}$, Yoko Mikami ${ }^{2}$, James A White ${ }^{2}$, \\ Matthias G Friedrich ${ }^{3}$, Leon Axel ${ }^{1}$ \\ From 18th Annual SCMR Scientific Sessions \\ Nice, France. 4-7 February 2015
}

\section{Background}

CMR can be used to assess the structure and function of athletes' hearts. However, diastolic function is not routinely measured with CMR. Mitral annular (MA) motion, commonly assessed by tissue Doppler imaging, is an important element of diastole that may help to distinguish physiological remodeling from pathological processes of the heart. CMR has been shown to play a useful role in evaluating MA motion. This study aims to characterize the global left ventricular diastolic function in endurance athletes by $3 \mathrm{D}$ volume tracking of the MA, using conventional cine-CMR images.

\section{Methods}

CMR studies of 24 high-level endurance athletes (age $22 \pm 3$ ) were retrospectively selected from a database. Routine CMR studies from 39 patients with normal hearts (age $42 \pm 16$ ) and 29 hypertrophic cardiomyopathy $(\mathrm{HCM})$ patients (age $52 \pm 17$ ) with normal ejection fractions were included for comparison. Using normalized cross-correlation, feature-tracking of the atrioventricular junctions was performed over the cardiac cycle, in routine long-axis 2-, 3-, and 4-chamber cine-CMR views. This resulted in 6 spatial MA points per cardiac phase, which were interpolated with a spline for 3D MA reconstruction. The 3D volume swept out by the MA was then calculated; the net sweep volume at a given cardiac phase was derived from the sum of the incremental volumes starting from end-diastole.

The resultant 3D MA sweep volume curve and its first derivative were calculated. The following diastolic

${ }^{1}$ Radiology, New York University School of Medicine, New York, NY, USA Full list of author information is available at the end of the article variables were used (Figure 1): Peak sweep volume rates in early diastole $\left(\mathrm{PSR}_{\mathrm{E}}\right)$ and atrial systole $\left(\mathrm{PSR}_{\mathrm{A}}\right)$, normalized by end-systolic sweep volume (ESSV). Sweep volume acceleration time $\left(\mathrm{AT}_{\mathrm{SV}}\right)$ and deceleration time $\left(\mathrm{DT}_{\mathrm{SV}}\right)$ (relative to the $\mathrm{PSR}_{\mathrm{E}}$ time). 50\% diastolic sweep volume recovery ( $\mathrm{DSVRT}_{50}$ ), defined as the time required in diastole for the MA to recover $50 \%$ of its ESSV, normalized by RR interval. Analysis of variance with post-hoc test and binary logistic regression were used for statistical analyses.

\section{Results}

As seen in Figure 2, athletes had the fastest $\mathrm{PSR}_{\mathrm{E}}$, followed by the normal group and then the HCM group $\left(9.0 \pm 2.0\right.$ vs. $7.7 \pm 1.6$ vs. $5.7 \pm 2.0 \mathrm{~s}^{-1}$, respectively, $\mathrm{P}<$ $0.05) ; \mathrm{PSR}_{\mathrm{A}}$ was the lowest in athletes, higher in the normal group, and the highest in the HCM group ( $2.7 \pm$ 0.8 vs. $4.6 \pm 1.3$ vs. $6.4 \pm 2.0 \mathrm{~s}^{-1}$, respectively, $\mathrm{P}<0.05$ ); DSVRT $_{50}$ was the shortest in athletes, followed by the normal group and then the HCM group $(11.9 \pm 2.0$ vs. $15.7 \pm 4.1$ vs. $22.1 \pm 11.2 \%$, respectively, $\mathrm{P}<0.05)$. No statistical differences were observed in $\mathrm{AT}_{\mathrm{SV}}$ and $\mathrm{DT}_{\mathrm{SV}}$ between athletes and the normal group. Lastly, the $\mathrm{PSR}_{\mathrm{E}}: \mathrm{PSR}_{\mathrm{A}}$ ratio was a significant independent predictor of athletes over the normal group when controlling for age $(\mathrm{P}=0.035)$.

\section{Conclusions}

3D MA sweep volumes derived from cine-CMR demonstrated that athletes had significantly faster early diastolic relaxation, followed by reduced MA motion in atrial systole, and faster diastolic MA sweep volume recovery, when compared to normal subjects and HCM patients. 

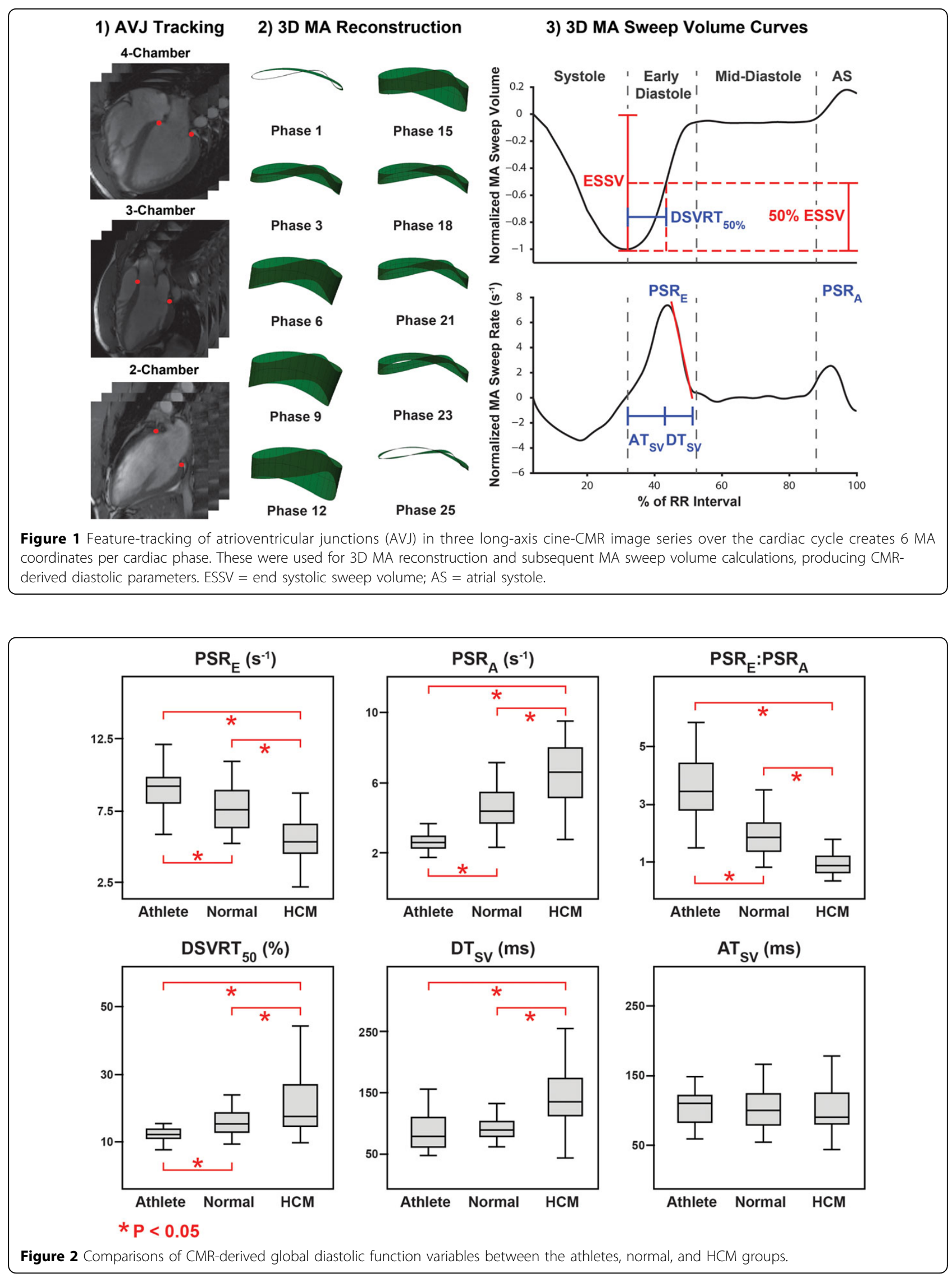


\section{Funding}

NIH R21-HL108218.

\section{Authors' details}

'Radiology, New York University School of Medicine, New York, NY, USA.

${ }^{2}$ Libin Cardiovascular Institute of Alberta, University of Calgary, Calgary, AB,

Canada. ${ }^{3}$ Montreal Heart Institute, Montreal, QC, Canada. ${ }^{4}$ University of

Ottawa Heart Institute, Ottawa, ON, Canada.

Published: 3 February 2015

doi:10.1186/1532-429X-17-S1-Q6

Cite this article as: Wu et al: Global diastolic function in endurance

athletes: three-dimensional volume tracking of the mitral annulus with cine-CMR. Journal of Cardiovascular Magnetic Resonance 2015 17(Suppl 1): Q6.

Submit your next manuscript to BioMed Central and take full advantage of:

- Convenient online submission

- Thorough peer review

- No space constraints or color figure charges

- Immediate publication on acceptance

- Inclusion in PubMed, CAS, Scopus and Google Scholar

- Research which is freely available for redistribution

Submit your manuscript at 